\title{
SCIENTIFIC REPORTS

\section{OPEN A microemulsion high-performance liquid chromatography (MELC) method for the separation and determination of hydrolyzed tenuifolin in Radix Polygalae}

\begin{abstract}
HuiYan ${ }^{1}$, Zhuan-Di Zheng ${ }^{1}$, Hong-Fei Wu ${ }^{1 *}$, Xiao-Chuang Liu ${ }^{3}$ \& An Zhou ${ }^{1,2 *}$
Tenuifolin was used as a reliable chemical marker for the quality control of Radix Polygalae. The determination of tenuifolin is challenging because the analyte molecule lacks a suitable chromophore. The aim of this study was to establish a microemulsion high-performance liquid chromatography (MELC) method which is robust and sensitive, and can separate and determine tenuifolin in Radix Polygalae using an oil-in-water $(\mathrm{O} / \mathrm{W})$ microemulsion mobile phase. The separations were performed on a C18 $(4.6 \times 250 \mathrm{~mm}, 5 \mu \mathrm{m})$ column at $25^{\circ} \mathrm{C}$ using a flow rate of $1.0 \mathrm{~mL} / \mathrm{min}$, and an ultraviolet detection wavelength of $210 \mathrm{~nm}$. The microemulsion mobile phase comprised $2.8 \%(\mathrm{w} / \mathrm{v})$ sodium dodecyl sulfate (SDS), $7.0 \%(v / v) n$-butanol, $0.8 \%(v / v) n$-octane and $0.1 \%(v / v)$ aqueous orthophosphate buffer (H3PO4). The linearity analysis of tenuifolin showed a correlation coefficient of 0.9923 in the concentration range of $48.00-960.00 \mu \mathrm{g} / \mathrm{mL}$. The accuracy of the method based on three concentration levels ranged from $96.23 \%$ to $99.28 \%$; the limit of detection (LOD) was $2.34 \mu \mathrm{g} / \mathrm{mL}$, and the limit of quantification (LOQ) was $6.76 \mu \mathrm{g} / \mathrm{mL}$. The results of our study indicated that the optimized MELC method was sensitive and robust, and can be widely applied for the separation and determination of tenuifolin in Radix Polygalae.
\end{abstract}

Radix Polygalae, named "YuanZhi" in traditional Chinese medicine, is the root of Polygala tenuifolia Willd. or Polygala sibirica $\mathrm{L}^{1}$. Modern pharmacological studies indicate that Radix Polygalae possesses various biological activities against certain ailments, such as cerebrovascular diseases, senile dementia and depression ${ }^{2-4}$. Moreover, some researchers found that Radix Polygalae could effectively suppress the consolidation and reinstatement of fear memories ${ }^{5}$. With the widespread clinical application of Radix Polygalae ${ }^{6,7}$, it is important to control the quality of Radix Polygalae. Tenuifolin is considered one of the main effective components of Radix Polygalae, which is beneficial for treating certain diseases of the central nervous system ${ }^{8,9}$. In addition, tenuifolin belongs to the chemical class of secondary saponins and exhibits stable chemical properties ${ }^{9}$. Therefore, tenuifolin was applied for the evaluation of the quality of Radix Polygalae in this study. To better control the quality of Radix Polygalae, there was a need to establish a method to separate and determine the concentration of tenuifolin.

Over the years, various quantitative analysis methods for determination of tenuifolin including high performance liquid chromatography (HPLC) ${ }^{10}$, high performance capillary electrophoresis (HPCE) ${ }^{11}$ and liquid chromatography with tandem mass spectrometry (LC-MS/MS) ${ }^{12}$ have been developed. Due to poor ultraviolet absorptivity, tenuifolin can only be analyzed at low-ultraviolet wavelength detection with HPLC $(210 \mathrm{~nm}$, chemical structure of tenuifolin is shown in Fig. 1). CAD usually requires higher maintenance and less precision. LC-MS/MS has high sensitivity and specificity, however, It is generally used for in vivo drug analysis on the basis of economical and applicable principles. Therefore, it is necessary to develop a new effective, sensitive, selective, and accurate analytical method for the determination of tenuifolin in Radix Polygalae.

${ }^{1}$ Department of Pharmacy, Anhui University of Chinese Medicine, Hefei, Anhui, 230012, P. R. China. ${ }^{2}$ Anhui Province Key Laboratory of Chinese Medicinal Formula, Hefei, Anhui, 230012, P. R. China. ${ }^{3}$ The First Affiliated Hospital of Anhui University of Chinese Medicine, Hefei, 230026, P. R. China. *email: wuhongfei2009@126.com; anzhou@ ahtcm.edu.cn 


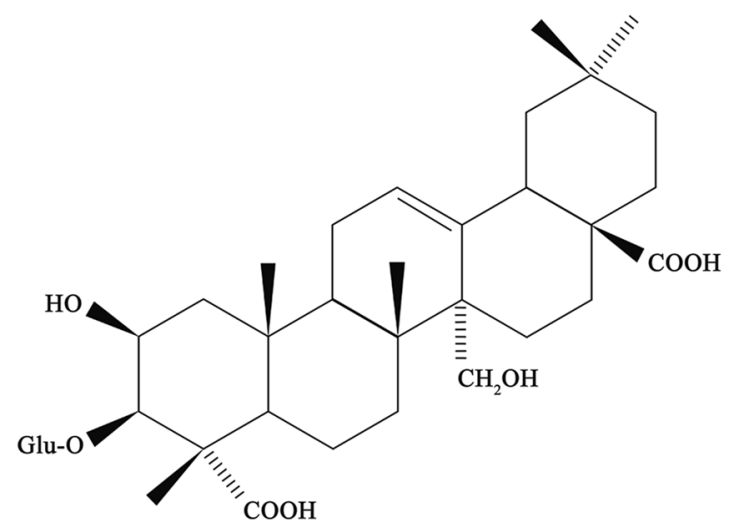

Figure 1. The chemical structure of tenuifolin.

Size Distribution by intensity

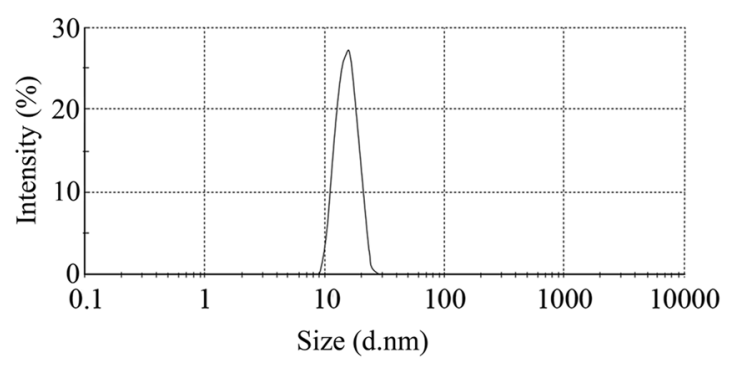

Figure 2. Size distribution (by intensity) of microemulsion mobile phase. The mobile phase consists of $2.8 \%$ $(\mathrm{w} / \mathrm{v})$ SDS, $7.0 \%(\mathrm{v} / \mathrm{v})$ n-butanol, $0.8 \%(\mathrm{v} / \mathrm{v})$ n-octane and $0.1 \%(\mathrm{v} / \mathrm{v}) \mathrm{H}_{3} \mathrm{PO}_{4}$ measured by the particle size analyzer.

The microemulsion high-performance liquid chromatography (MELC) method is a relatively new chromatographic technique ${ }^{13}$, that utilizes microemulsion as the mobile phase and has been shown to be suitable for the separation of pharmaceutical compounds using both isocratic and gradient elution modes. The MELC method has many advantages that are superior to conventional chromatography, such as less organic solvent and lower $\operatorname{cost}^{14}$. MELC has comparable or higher selectivity and separation efficiency than conventional HPLC systems ${ }^{15}$. The microemulsion formulation has a crucial effect on the separation and retention. Additionally, MELC is usful for low-ultraviolet detection wavelengths $(190 \mathrm{~nm})$ with high sensitivity for weak chromophore compounds. When the chromophore was limited, the detection was superior to conventional HPLC ${ }^{16}$. MELC has been successfully applied to determine drugs in pharmaceutical dosage form ${ }^{17,18}$, to analyze biological samples ${ }^{19,20}$, and to separate and determine content in Chinese traditional medicine ${ }^{21,22}$.

In the present work, we investigated the possibility of separation and determination of tenuifolin in Radix Polygalae by reversed-phase high-performance liquid chromatography using an oil-in-water microemulsion as the mobile phase. Moreover, some critical parameters affecting the separation and determination selectivity of the MELC system, such as the surfactant, the cosurfactant, the oil phase and the temperature, were studied in detail.

\section{Results and Discussion}

Particle size of the mobile phase. The average particle size of the microemulsion was detected by three repeated assays. The particle size of the microemulsion mobile phase was $15.57 \pm 2.95 \mathrm{~nm}$ (Fig. 2). In addition, the microemulsion system remained relatively stable during the experiment.

Optimization of MELC conditions. Selection of surfactant type and concentration. The surfactant in the mobile phase has a remarkable effect on the separation selectivity in the mobile phase. The surfactant can change the surface of the stationary phase because it can adhere to the porous stationary phase, which has a direct influence on the retention of solutes ${ }^{23}$. In this study, SDS, CTAB and Tween- 80 were tested for using in the oil-in-water microemulsion. Both CTAB and Tween- 80 failed to offer a better baseline resolution and separation for tenuifolin. Therefore, SDS was the optimal surfactant in this study. Five concentrations of SDS were studied (Fig. 3a). It was found that the retention time of tenuifolin decreased upon increasing the concentration of SDS from 2.6 to $3.2 \% \mathrm{w} / \mathrm{v}$. This showed that SDS may have changed the surface of the stationary phase and therefore reduced the retention of tenuifolin. However, further increases in SDS concentration has shown no marked effect on the retention time of tenuifolin. $2.8 \% \mathrm{w} / \mathrm{v}$ SDS could provide a more appropriate elution time for separation and better retention factors for tenuifolin in Radix Polygalae. Therefore, $2.8 \% \mathrm{w} / \mathrm{v}$ SDS was used as the surfactant for further studies. 

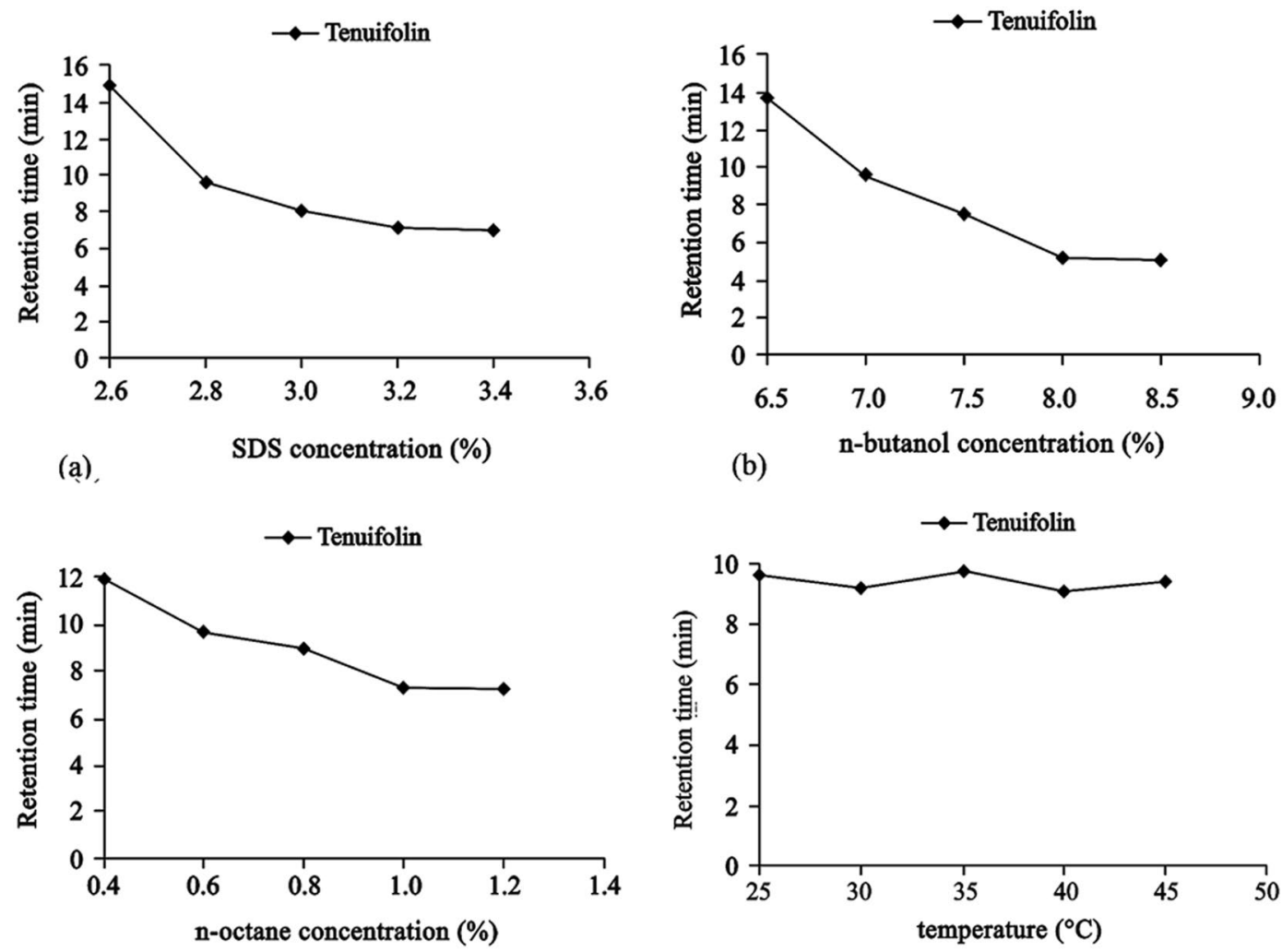

(c)

(d)

Figure 3. (a) Effect of SDS concentration $(\%, w / v)$ in the microemulsion on the retention time of tenuifolin using microemulsion mobile phases consisting of different concentrations of SDS, $7.0 \% \mathrm{v} / \mathrm{v} \mathrm{n}$-butanol and $0.8 \% \mathrm{v} / \mathrm{v}$ n-octane. (b) Effect of $\mathrm{n}$-butanol concentration $(\%, \mathrm{v} / \mathrm{v})$ in the microemulsion on the retention time of tenuifolin using microemulsion mobile phases consisting of different concentrations of $n$-butanol, $2.8 \% \mathrm{w} / \mathrm{v}$ SDS and $0.8 \% \mathrm{v} / \mathrm{v} \mathrm{n}$-octane. (c) Effect of $\mathrm{n}$-octane concentration $(\%, \mathrm{v} / \mathrm{v})$ in the microemulsion on the retention time of tenuifolin using microemulsion mobile phases consisting of different concentrations of n-octane, $2.8 \%$ $\mathrm{v} / \mathrm{v}$ SDS and $7.0 \% \mathrm{v} / \mathrm{v}$ n-butanol. (d) Effect of column temperature $\left({ }^{\circ} \mathrm{C}\right)$ on the retention time of tenuifolin using microemulsion mobile phases consisting of $2.8 \% \mathrm{v} / \mathrm{v}$ SDS, $7.0 \% \mathrm{v} / \mathrm{v} \mathrm{n}$-butanol and $0.8 \% \mathrm{v} / \mathrm{v}$ n-octane.

Selection of cosurfactant type and concentration. A cosurfactant, for instance, a short-chain alcohol was utilized to enhance and stabilize the microemulsion system. Moreover, cosurfactants play important role in phase behavior $^{24}$. 1,2-propanediol, n-propanol and n-butanol were used as cosurfactants, with which the retention times for tenuifolin were found to be $24.01 \mathrm{~min}, 16.23 \mathrm{~min}$ and $9.66 \mathrm{~min}$, respectively, and the symmetry factors were 0.57 , 0.73 and 0.94 , respectively. Therefore, the optimum cosurfactant was n-butanol in this study. Five concentrations of n-butanol were investigated $(6.5,7.0,7.5,8.0$ and $8.5 \% \mathrm{v} / \mathrm{v})$ (Fig. 3b). The retention time of tenuifolin was reduced upon increasing the concentration of $\mathrm{n}$-butanol from 6.5 to $8.0 \% \mathrm{v} / \mathrm{v}$, which was due to an increase in the solubilization capacity of the microemulsion with the use of n-butanol. Nevertheless, a further increase in the n-butanol concentration had no marked effect on the retention time. The use of $7.0 \% \mathrm{v} / \mathrm{v} \mathrm{n}$-butanol provided a better separation selectivity and suitable elution time for tenuifolin in Radix Polygalae. Therefore, 7.0\% v/v n-butanol was chosen as the optimal cosurfactant concentration in subsequent experiments.

Selection of oil type and concentration. The type and concentration of the oil phase can significantly affect the retention time of analytes in the MELC method ${ }^{25}$. Three types of organic solvents ( $\mathrm{n}$-hexane, $\mathrm{n}$-heptane and $\mathrm{n}$-octane) were investigated in this study. However, $\mathrm{n}$-hexane and $\mathrm{n}$-heptane made forming stable microemulsions difficult. Therefore, n-octane was chosen as the oil type. Five concentrations of n-octane were investigated (0.4, $0.6,0.8,1.0$ and $1.2 \% \mathrm{v} / \mathrm{v}$ ) (Fig. $3 \mathrm{c}$ ), which showed that the retention time of tenuifolin decreased as the n-octane concentration increased from 0.4 to $1.0 \% \mathrm{w} / \mathrm{v}$. However, with a further increases in the n-octane concentration, the retention time of tenuifolin did not change significantly. The augmentation of $n$-octane can increase the content of organic reagents in the mobile phase and improve the elution ability. The n-octane molecule can also interfere with the surface of the stationary phase to reduce the polarity of the stationary phase and enhance the elution ability. A concentration of $0.8 \% \mathrm{v} / \mathrm{v}$ was suitable for routine use to separate tenuifolin in Radix Polygalae as it provides good peak efficiency and suitable elution time.

Selection of column temperature. Five different column temperatures $\left(25,30,35,40\right.$ and $\left.45^{\circ} \mathrm{C}\right)$ were examined in this study (Fig. 3d). It was found that the retention time of tenuifolin was not significantly affected by temperature change. The result was in line with the findings reported ${ }^{26}$. However, the temperature has a significant effect on 
(a) $25^{\circ} \mathrm{C}$

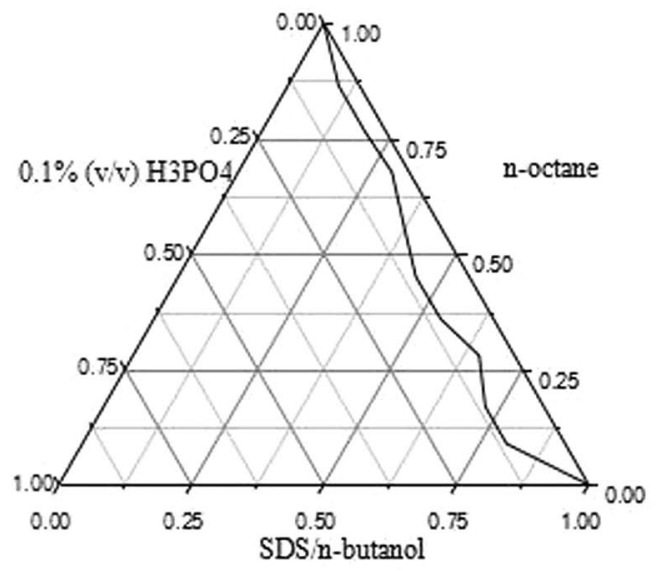

(c) $35^{\circ} \mathrm{C}$

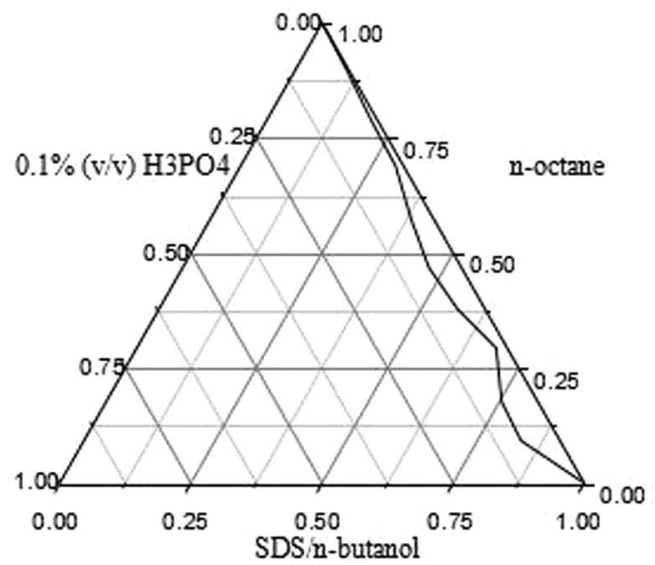

(b) $30^{\circ} \mathrm{C}$

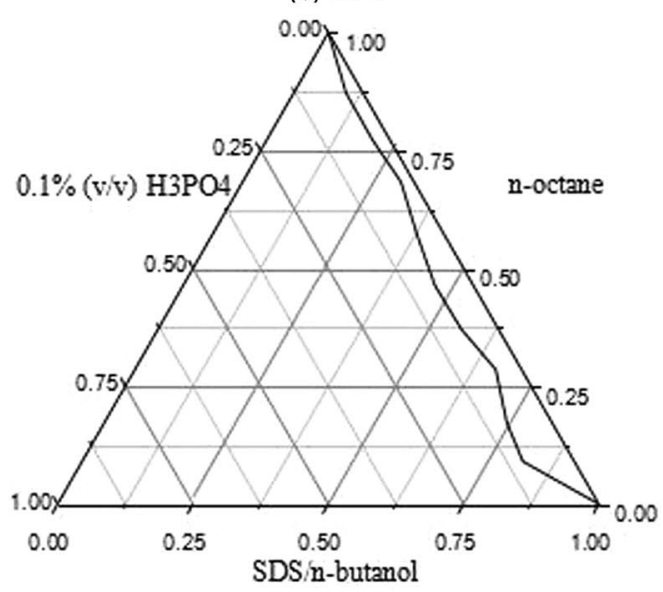

(d) $40^{\circ} \mathrm{C}$

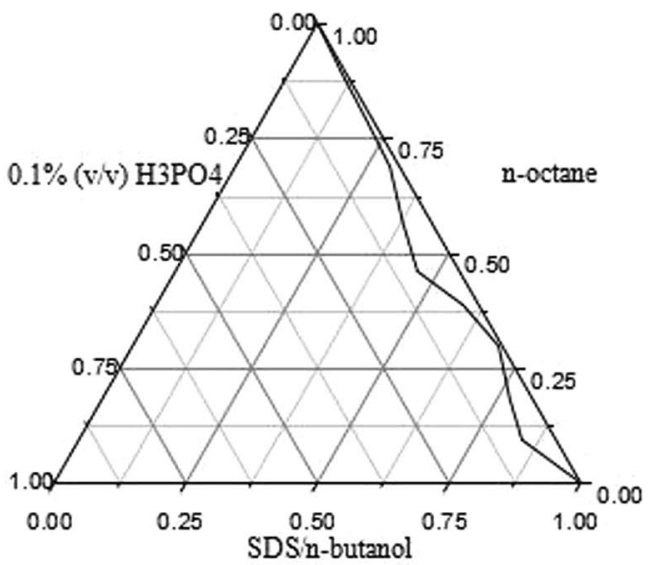

(e) $45^{\circ} \mathrm{C}$

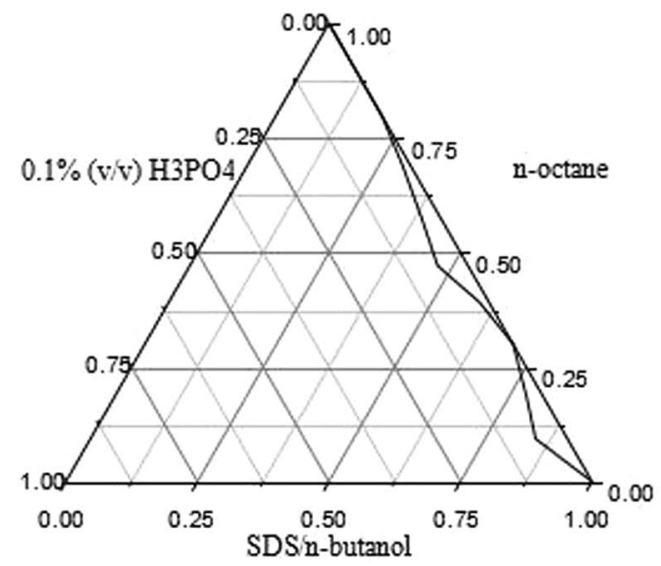

Figure 4. We select SDS and n-butanol as surfactant and cosurfactant, n-octane as oil phase, $0.1 \% \mathrm{H} 3 \mathrm{PO} 4$ as water phase to draw pseudo-ternary phase diagram. (a) A pseudo-ternary phase diagram of a W/O-type nanoemulsion region at $25^{\circ} \mathrm{C}$. (b) A pseudo-ternary phase diagram of a W/O-type nanoemulsion region at $30^{\circ} \mathrm{C}$. (c) A pseudo-ternary phase diagram of a W/O-type nanoemulsion region at $35^{\circ} \mathrm{C}$. (d) A pseudo-ternary phase diagram of a W/O-type nanoemulsion region at $40^{\circ} \mathrm{C}$. (e) A pseudo-ternary phase diagram of a W/Otype nanoemulsion region at $45^{\circ} \mathrm{C}$.

the area of the microemulsion region. With increases in the temperature, the area of the microemulsion region was reduced and the stability of microemulsion was decreased. Finally, to protect the chromatographic column and maintain the stability of microemulsion, $25^{\circ} \mathrm{C}$ was selected from this study (Fig. 4). 


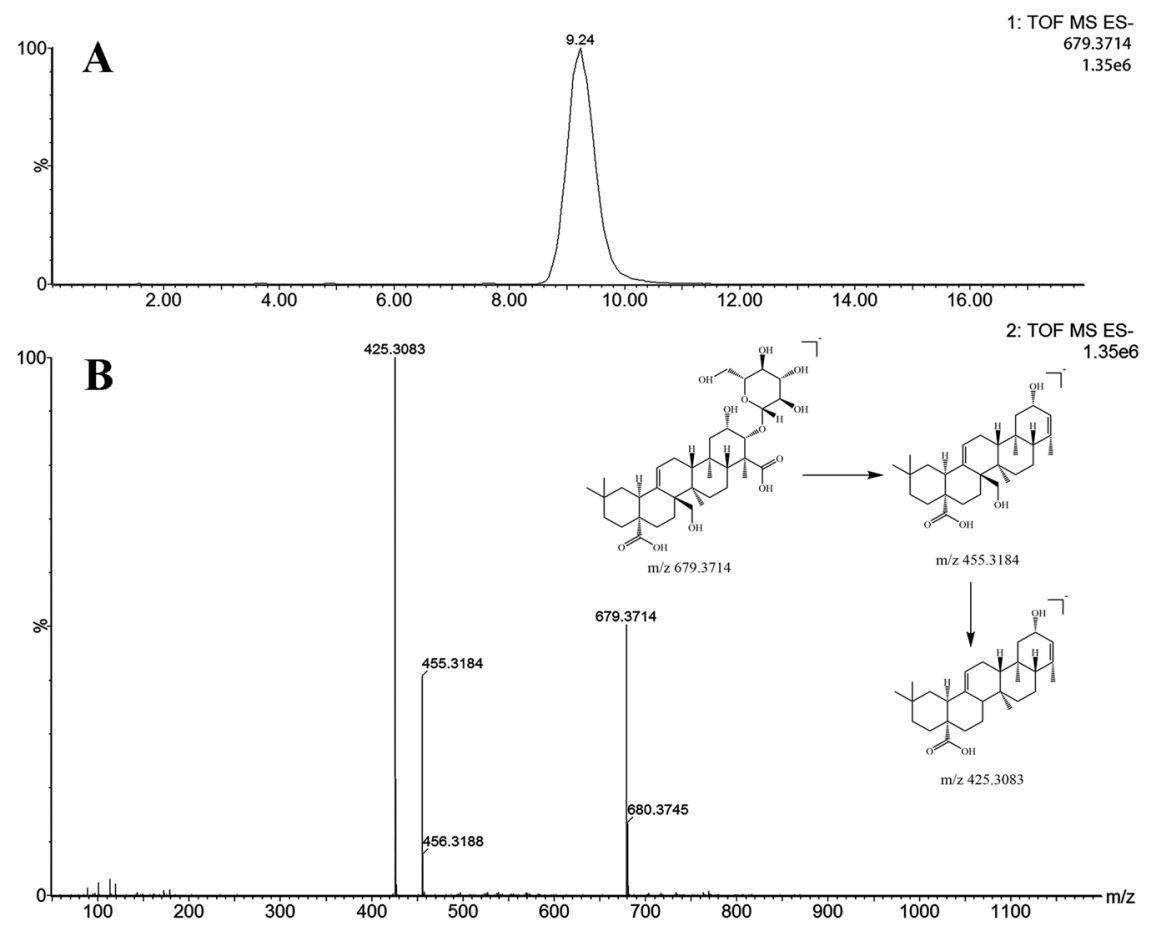

Figure 5. Extracted ion chromatograms (EICs) and MS/MS spectra of tenuifolin.
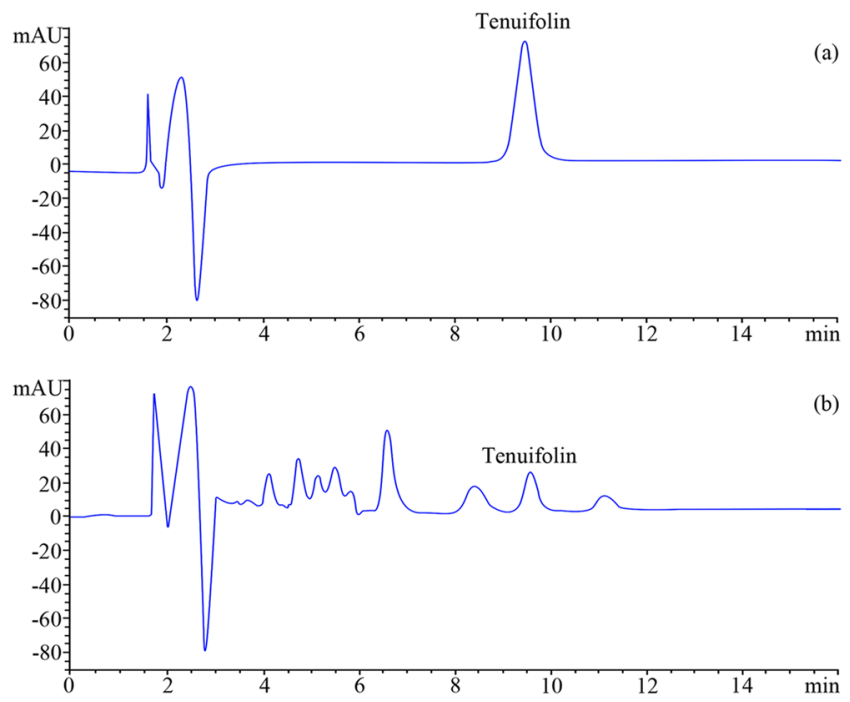

Figure 6. MELC chromatograms of (a) the standard solution and (b) the sample solution.

Validation of chromatographic parameters. Identification of tenuifolin. In order to identify the tenuifolin, an aliquot of $5 \mu \mathrm{L}$ filtrate $(48.00 \mu \mathrm{g} / \mathrm{mL})$ was injected into the UPLC-Q-TOF-MSE system for analysis. The total ion current (TIC) chromatogram and MS/MS spectra including proposed fragmentation path ways of tenuifolin in negative modes are depicted in Fig. 5. Tenuifolin showed quasi-molecular ion $[\mathrm{M}-\mathrm{H}]$ at $\mathrm{m} / \mathrm{z} 679.3714$ in negative ion mode, and yielded fragment ions at $\mathrm{m} / \mathrm{z} 455.3184$ and 425.3083 respectively. According to the accurate mass and its fragment information, it was identified as tenuifolin.

Selectivity, linearity and sensitivity. Selectivity was confirmed in the chromatograms of the standard solution and the sample solution. It is apparent that tenuifolin was clearly baseline separated in the sample solution, eluting in less than $10 \mathrm{~min}$. The optimized separation is demonstrated in Fig. 6. Method linearity was evaluated in the range of $48.00-960.00 \mu \mathrm{g} / \mathrm{mL}$. The regression equation was as follows Eq. (1):

$$
y=169.27 x+31.32
$$




\begin{tabular}{|l|l|}
\hline $\begin{array}{l}\text { Concentration } \\
(\boldsymbol{\mu g} / \mathrm{mL})\end{array}$ & Peak area \\
\hline 48 & 8799.28 \\
96 & 16263.24 \\
\hline 192 & 30356.71 \\
\hline 400 & 69718.33 \\
\hline 640 & 108229.02 \\
\hline 960 & 162176.52 \\
\hline
\end{tabular}

Table 1. Linearity date of the MELC method.

\begin{tabular}{|c|c|c|c|c|}
\hline \multirow{2}{*}{$\begin{array}{l}\text { Nominal } \\
\text { concentration } \\
(\mu \mathrm{g} / \mathrm{mL})\end{array}$} & \multicolumn{2}{|l|}{ Intra-day } & \multicolumn{2}{|l|}{ Inter-day } \\
\hline & $\begin{array}{l}\text { Amount found Mean } \\
(\mathrm{N}=5) \pm \mathrm{SD}\end{array}$ & $\begin{array}{l}\text { Precision } \\
\text { (\% RSD) }\end{array}$ & $\begin{array}{l}\text { Amount found Mean } \\
(\mathrm{N}=15) \pm S D\end{array}$ & $\begin{array}{l}\text { Precision } \\
\text { (\% RSD) }\end{array}$ \\
\hline 48.00 & $47.02 \pm 0.47$ & 0.98 & $47.55 \pm 0.73$ & 1.54 \\
\hline 480.00 & $478.02 \pm 1.93$ & 0.40 & $477.80 \pm 2.60$ & 0.54 \\
\hline 960.00 & $958.12 \pm 2.16$ & 0.23 & $958.43 \pm 2.59$ & 0.27 \\
\hline
\end{tabular}

Table 2. Intra-day and Inter-day precision date of the MELC method.

\begin{tabular}{|l|l|l|l|l|l|}
\hline $\begin{array}{l}\text { Original } \\
\text { amount } \\
(\mathbf{m g})\end{array}$ & $\begin{array}{l}\text { Spiked } \\
\text { amount } \\
(\mathbf{m g})\end{array}$ & $\begin{array}{l}\text { Found } \\
\text { amount } \\
(\mathbf{m g})\end{array}$ & $\begin{array}{l}\text { Recovery } \\
(\%)\end{array}$ & $\begin{array}{l}\text { Average } \\
\text { recovery } \\
(\%)\end{array}$ & $\begin{array}{l}\text { RSD } \\
(\%)\end{array}$ \\
\hline 10.76 & 8.68 & 19.08 & 96.65 & & \\
\hline 10.68 & 8.68 & 18.92 & 95.88 & 96.23 & 0.41 \\
\hline 10.64 & 8.68 & 18.91 & 96.15 & & \\
\hline 10.81 & 10.85 & 21.42 & 97.78 & & \\
\hline 10.89 & 10.85 & 21.41 & 96.97 & 98.13 & 1.39 \\
\hline 10.72 & 10.85 & 21.53 & 99.63 & & \\
\hline 10.59 & 13.02 & 23.41 & 98.11 & & \\
\hline 10.66 & 13.02 & 23.76 & 100.75 & 99.28 & 1.36 \\
\hline 10.68 & 13.02 & 23.59 & 98.97 & & \\
\hline
\end{tabular}

Table 3. Recovery of tenuifolin in Radix Polygalae.

where $y$ is the peak area and $x$ is the concentration $(\mu \mathrm{g} / \mathrm{mL})$ (Table 1). The linear regression analysis data showed a good linear relationship with a correlation coefficient $(r)$ of 0.999 . The LOD and LOQ values were 2.34 and $6.76 \mu \mathrm{g} / \mathrm{mL}$, respectively, which showed high sensitivity under the experimental conditions.

Precision and accuracy. The intraday and interday variations are summarized in Table 2 . The RSD were less than $0.98 \%$ and $1.54 \%$ for intraday and interday variation, respectively. The average recoveries ranged from $96.23 \%$ to 99.28\%. The RSD values were $0.41 \%, 1.39 \%$ and $1.36 \%$, respectively (Table 3 ). The results suggested the feasibility of the MELC method for detecting tenuifolin in Radix Polygalae.

Repeatability and stability. For the repeatability study, the result showed that the value of RSD was $1.98 \%$, which indicated that our method was reproducible. The stability was assessed by the same sample solution. The value of RSD for tenuifolin was $1.42 \%$, indicating that the sample solution remained stable for at least 24 hours.

Comparison with conventional HPLC analysis. To prove the validity of the MELC method, the results obtained by use of the proposed method were compared with conventional HPLC analysis. A conventional HPLC gradient mobile phase of methanol- $0.05 \%$ aqueous phosphoric acid (70:30) was employed. Compared with conventional HPLC analysis, the MELC method has a lower detection limit and higher sensitivity under identical experimental conditions $^{26}$. The LOD of tenuifolin by way of HPLC was $3.50 \mu \mathrm{g} / \mathrm{mL}$, and the LOD of tenuifolin with MELC was $2.34 \mu \mathrm{g} / \mathrm{mL}$. The LOQ of tenuifolin with HPLC was $7.50 \mu \mathrm{g} / \mathrm{mL}$, and the LOQ of tenuifolin in the MELC method was $6.76 \mu \mathrm{g} / \mathrm{mL}$.

Application of the method. The validated method was applied to determine the tenuifolin contents in ten different samples of Radix Polygalae collected from various regions of China. The MELC results showed that the content varied between 0.83 and $3.21 \%$. The HPLC results showed that the content varied between 0.71 and $2.98 \%$. The results of the two methods are consistent. Among them, the contents of tenuifolin in Radix Polygalae sample No. 2 were markedly higher than those in samples collected from other regions (Table 4). 


\begin{tabular}{|c|c|c|c|c|}
\hline \multirow[b]{2}{*}{ No. } & \multicolumn{2}{|l|}{ HPLC } & \multicolumn{2}{|l|}{ MELC } \\
\hline & $\begin{array}{l}\text { Mean content } \\
(\%)\end{array}$ & $\begin{array}{l}\text { RSD } \\
(\%)\end{array}$ & $\begin{array}{l}\text { Mean content } \\
(\%)\end{array}$ & $\begin{array}{l}\text { RSD } \\
(\%)\end{array}$ \\
\hline 1 & 2.41 & 0.98 & 2.82 & 0.87 \\
\hline 2 & 2.98 & 1.32 & 3.21 & 1.12 \\
\hline 3 & 2.03 & 1.14 & 2.62 & 1.04 \\
\hline 4 & 1.86 & 1.09 & 2.14 & 0.79 \\
\hline 5 & 2.29 & 0.88 & 2.27 & 1.07 \\
\hline 6 & 0.71 & 1.17 & 0.83 & 1.12 \\
\hline 7 & 0.87 & 1.24 & 0.92 & 1.76 \\
\hline 8 & 1.39 & 1.67 & 1.47 & 0.81 \\
\hline 9 & 1.41 & 1.91 & 1.29 & 1.22 \\
\hline 10 & 1.21 & 1.31 & 1.50 & 0.91 \\
\hline
\end{tabular}

Table 4. The content of tenuifolin in Radix Polygalae $(\mathrm{N}=3)$.

\section{Conclusions}

A sensitive, simple and efficient MELC method was developed for the rapid detection of tenuifolin in Radix Polygalae. Compared with HPLC, MELC method uses less organic solvent and offers a faster analysis time for the determination of tenuifolin with previous ${ }^{10}$. In addition, the proposed method is characterized by a high degree of sensitivity, precision, accuracy and separation. The method was successfully applied to samples of Radix Polygalae from different regions of China. In future research, the chromatographic conditions in this paper could be used to analyze tenuifolin in other biological samples, such as tissue homogenates, plasma and urine. Although the MELC assay is not a substitute for a more accurate and sensitive assay based on LC-MS/MS, the MELC method could provide a new choice for the routine quality control analysis of traditional Chinese medicinal materials as a powerful tool.

\section{Materials and Methods}

Chemicals. Sodium dodecyl sulfate (SDS), cetyltrimethyl ammonium bromide (CTAB) and Tween-80 were obtained from Sinopharm Chemical Reagent Co., Ltd. (Shanghai, China). N-butanol, n-propanol and 1,2-propanediol of HPLC grade were obtained from Oupo Bio-Technique Co., Ltd. (Shanghai, China). N-octane, n-hexane and n-heptane were all of HPLC grade and purchased from Bodi Chemicals Co., Ltd. (Tianjin, China). Tenuifolin (purity $>98.0 \%$, lot number: 111849-201001) was purchased from Shijiazhuang QiDI Biological Technology Co., Ltd. (Shijiazhuang, China). Ten samples of Radix Polygalae were collected from Wanrong, Yuncheng, and Jiang counties of Shanxi Province and from Xinmi and Yuzhou Counties of Henan Province, and identified by Professor Xian-Hua Liu from the Anhui University of Chinese Medicine. All of the above reagents and chemicals were of analytical grade.

Chromatographic conditions. The analyses were carried out using an Agilent Technologies 1100 HPLC system (USA) with a Welch Materials XB- $\mathrm{C}_{18}(4.6 \times 250 \mathrm{~mm}, 5 \mu \mathrm{m})$ column. A microemulsion as the mobile phase was prepared by mixing $2.8 \%$ (w/v) SDS, $7.0 \%(\mathrm{v} / \mathrm{v}) \mathrm{n}$-butanol, $0.8 \%(\mathrm{v} / \mathrm{v})$ n-octane and $0.1 \%(\mathrm{v} / \mathrm{v}) \mathrm{H}_{3} \mathrm{PO}_{4}$. Before being injected into the HPLC system, the microemulsion mobile phase was filtered through $0.22 \mu \mathrm{m}$ nylon membrane filters. During the analyses, the column temperature was set at $25^{\circ} \mathrm{C}$, and the injection volume was $10 \mu \mathrm{L}$. The flow rate of the mobile phase was controlled at $1.0 \mathrm{~mL} / \mathrm{min}$ and peaks were detected at $210 \mathrm{~nm}^{21,22}$.

Preparation of sample solutions. Approximately $1.0 \mathrm{~g}$ of Radix Polygalae powder (passing through a No. 3 sieve, $355 \pm 13 \mu \mathrm{m}$ ) was extracted with $50 \mathrm{~mL}$ of $70 \%$ methanol in an ultrasonic bath for $1 \mathrm{~h}$. After cooling, it was brought up to the initial volume with $70 \%$ methanol and then filtered through filter paper. The filtrate $(25 \mathrm{~mL})$ was transferred to a round bottom flask and evaporated to dryness. Then, $25 \mathrm{~mL}$ of $10 \%$ sodium hydroxide was added to the residue. The solution was heated and refluxed for $2 \mathrm{~h}$, and the $\mathrm{pH}$ was adjusted to 4 with concentrated hydrochloric acid after cooling. The mixture was extracted by using $50 \mathrm{~mL}$ of $\mathrm{n}$-butanol three times. The extraction solutions were collected and concentrated to dryness, dissolved with methanol and moved into a $25 \mathrm{~mL}$ volumetric flask ${ }^{27}$. Before being injected, the solution was filtered by $0.22 \mu \mathrm{m}$ nylon membrane filters.

Preparation of working standard solutions. A standard solution of tenuifolin was prepared by accurately weighing $60 \mathrm{mg}$ of the analyte and dissolving it in a $50 \mathrm{~mL}$ volumetric flask using methanol. The standard solutions $(1.20 \mathrm{mg} / \mathrm{mL})$ were diluted directly to appropriate concentrations with methanol to produce the working standard solutions. All standard solutions were passed through $0.22 \mu \mathrm{m}$ nylon membrane filters before analysis.

Preparation of microemulsion. The microemulsion contained SDS (2.8\%, w/v), n-butanol (7.0\%, v/v) and $\mathrm{n}$-octane $(0.8 \%, \mathrm{v} / \mathrm{v})$ as the surfactant, cosurfactant and oil phase, respectively. Briefly, a certain amount of SDS, $\mathrm{n}$-butanol and $\mathrm{n}$-octane were mixed in an ultrasonic bath for $10 \mathrm{~min}$. Then, $0.01 \%(\mathrm{v} / \mathrm{v}) \mathrm{H}_{3} \mathrm{PO}_{4}$ was added to the mixed system and mixed in an ultrasonic bath for $30 \mathrm{~min}$.

Particle size measurement of the mobile phase. The microemulsion mobile phase consisting of $2.8 \%$ $(\mathrm{w} / \mathrm{v})$ SDS, $7.0 \%(\mathrm{v} / \mathrm{v}) \mathrm{n}$-butanol, $0.8 \%(\mathrm{v} / \mathrm{v}) \mathrm{n}$-octane and $0.1 \%(\mathrm{v} / \mathrm{v}) \mathrm{H}_{3} \mathrm{PO}_{4}$ was filtered through $0.22 \mu \mathrm{m}$ filters. 
The reported size was the $\mathrm{Z}$-average size (cumulant mean) of three replicates determined at $25^{\circ} \mathrm{C}$ using a particle size analyzer (Malvern, UK).

Method validation. Suitability of the optimized MELC method for the analysis of tenuifolin was evaluated with validation studies including specificity, linearity, sensitivity, limit of detection (LOD), limit of quantification (LOQ), repeatability, accuracy and stability of the sample solution.

Specificity, linearity and sensitivity. Specificity was evaluated by comparing the chromatograms of the standard solution and the sample solution. The linear dynamic range was selected within $48.00-960.00 \mu \mathrm{g} / \mathrm{mL}$. Six different concentrations of tenuifolin were prepared at 48.00, 96.00, 192.00, 400.00, 640.00 and $960.00 \mu \mathrm{g} / \mathrm{mL}$. The calibration curve was obtained over this range by plotting the peak area against the concentration of tenuifolin. Sensitivity was expressed by the LOD and LOQ, which were determined by signal-to-noise ratios greater than 3 and 10 , respectively.

Precision and accuracy. Precision of the method was represented by the measurement of the intraday and interday variations of standard solutions at low $(48.00 \mu \mathrm{g} / \mathrm{mL})$, middle $(480.00 \mu \mathrm{g} / \mathrm{mL})$ and high $(960.00 \mu \mathrm{g} / \mathrm{mL}) \mathrm{con}$ centration levels. The variations were expressed as the relative standard deviations (RSD). Intraday variation was determined for five replicates on the same day. Interday variation was evaluated by analyzing five replicates on three successive days. The accuracy of the method was determined by recovery studies using the standard addition method. Known amounts of teuifolin at three levels $(8.68,10.85$, and $13.02 \mathrm{mg})$ were spiked into approximately $0.50 \mathrm{~g}$ of Radix Polygalae powder sourced from Xinmi of Henan Province, and then extracted and analyzed as described above. Recovery was calculated by Eq. (2).

$$
\text { recovery }(\%)=\frac{\text { amount found }- \text { original amount }}{\text { amount spiked }} \times 100 \%
$$

Repeatability and stability. Repeatability was evaluated under optimum conditions by injecting six sample solutions at the same concentration that were extracted from the same batch of Xinmi. Stability was tested within the same sample solution stored at room temperature and assayed at $0,2,4,8,12$ and $24 \mathrm{~h}$.

\section{Data availability}

The datasets generated during and/or analyzed during the current study are available from the corresponding author on reasonable request.

Received: 14 January 2019; Accepted: 27 November 2019;

Published online: 13 December 2019

\section{References}

1. Li, J. et al. Simultaneous determination of phenols in Radix Polygalae by high performance liquid chromatography: quality assurance of herbs from different regions and seasons. J Sep Sci. 30, 2583-2589 (2007).

2. Choi, J. G. et al. Polygalae Radix inhibits toxin-induced neuronal death in the Parkinson's disease models. J Ethnopharmacol. 134, 414-421 (2011).

3. Zhao, H., Wang, Z. C., Wang, K. F. \& Chen, X. Y. A $\beta$ peptide secretion is reduced by Radix Polygalae-induced autophagy via activation of the AMPK/mTOR pathway. Mol Med Rep. 12, 2771-2776 (2015).

4. Shin, J. W. et al. Reduced consolidation, reinstatement, and renewal of conditioned fear memory by repetitive treatment of Radix Polygalae in mice. Front Psychiatry. 8, 97 (2017).

5. Liu, P. et al. Potential antidepressant properties of Radix Polygalae (Yuan Zhi). Phytomedicine. 17, 794-799 (2010).

6. Chen, L. P., Wang, F. W., Zuo, F., Jia, J. J. \& Jiao, W. G. Clinical Research on Comprehensive Treatment of Senile Vascular Dementia. Journal of Traditional Chinese Medicine. 31, 178-181 (2011).

7. Qiu, H. et al. Dihuang Yinzi, a classical Chinese herbal prescription, for Amyotrophic Lateral Sclerosis: a 12-year follow-up case report. Medicine (Baltimore). 95, e3324 (2016).

8. Cao, Q. et al. Tenuifolin, a saponin derived from Radix Polygalae, exhibits sleep-enhancing effects in mice. Phytomedicine. 23, 1797-1805 (2016).

9. Liu, Y. M. et al. Tenuifolin, a secondary saponin from hydrolysates of polygala saponins, counteracts the neurotoxicity induced by $\mathrm{A} \beta_{25-35}$ peptides in vitro and in vivo. Pharmacol Biochem Behav. 128, 14-22 (2015).

10. Li, J. et al. HPLC determination of total saponins in Radix Polygalae. Chin. J. Pharm Anol. 27, 1329-1332 (2007).

11. Hao, Z. Y., Wang, J., Zhang, Y. M. \& Chen, A. J. Determination of tenuifolin in Polygalae Radix from different regions by RF-HPCE. J. Chin Pharm Sci. 20, 342-346 (2011).

12. Ma, B. et al. Quantitative analysis of tenuifolin concentrations in rat plasma and tissue using LCMS/MS: application to pharmacokinetic and tissue distribution study. J Pharm Biomed Anal. 88, 191-200 (2014).

13. Anđelija, M., Darko, I., Biljana, S. J. \& Mirjana, M. Robustness Testing of Microemulsion Liquid Chromatographic Separation of Simvastatin and its Impurities. Journal of Liquid Chromatography \& Related Technologies. 32, 874-889 (2009).

14. Li, L., Lai, C., Xuan, X., Gao, C. \& Li, N. Simultaneous determination of hydrochlorothiazide and losartan potassium in osmotic pump tablets by microemulsion liquid chromatography. J Chromatogr Sci. 54, 1415-1420 (2016).

15. Malenović, A., Jančić-Stojanović, B., Ivanović, D. \& Medenica, M. Forced degradation studies of simvastatin using microemulsion liquid chromatography. Journal of Liquid Chromatography \& Related Technologies. 33, 536-547 (2010).

16. Altria, K. D., Marsh, A. \& Clark, B. J. High performance liquid chromatographic analysis of pharmaceuticals using oil-in-water microemulsion eluent and monolithic column. Chromatographia. 63, 309-314 (2006).

17. Hammouda, M. E., Abu El-Enin, M. A., El-Sherbiny, D. T., El-Wasseef, D. R. \& El-Ashry, S. M. Simultaneous determination of enalapril and hydrochlorothiazide in pharmaceutical preparations using microemulsion liquid chromatography. J Chromatogr Sci. 53, 90-96 (2015).

18. Momenbeik, F., Roosta, M. \& Nikoukar, A. A. Simultaneous microemulsion liquid chromatographic analysis of fat-soluble vitamins in pharmaceutical formulations: optimization using genetic algorithm. J Chromatogr A. 1217, 3770-3773 (2010). 
19. Abou-Taleb, N. H., El-Wasseef, D. R., El-Sherbiny, D. T. \& El-Ashry, S. M. Multiobjective optimization strategy based on desirability functions used for the microemulsion liquid chromatographic separation and quantification of norfloxacin and tinidazole in plasma and formulations. J Sep Sci. 38, 901-908 (2015).

20. Gao, H., Huang, H., Zheng, A., Yu, N. \& Li, N. Determination of quantitative retention-activity relationships between pharmacokinetic parameters and biological effectiveness fingerprints of Salvia miltiorrhiza constituents using biopartitioning and microemulsion high-performance liquid chromatography. J Chromatogr B Analyt Technol Biomed Life Sci. 1067, 10-17 (2017).

21. Huang, H. et al. Optimization of liquid chromatographic method for the separation of nine hdrophilic and hydrophobic components in Salviae miltiorrhizae Radix et Rhizoma (Danshen) using microemulsion as eluent. J Chromatogr B Analyt Technol Biomed Life Sci. 955-956, 124-133 (2014).

22. Song, R. \& Zhou, J. Microemulsion liquid chromatographic method for simultaneous separation and determination of six flavonoids of Apocynum venetum leaf extract. J Chromatogr B Analyt Technol Biomed Life Sci. 995-996, 8-14 (2015).

23. Marsh, A., Clark, B. \& Altria, K. Oil-in-Water Microemulsion High Performance Liquid Chromatographic Analysis of Pharmaceuticals. Chromatographia. 59 (2004).

24. Garti, N., Yaghmur, A., Leser, M. E., Clement, V. \& Watzke, H. J. Improved Oil Solubilization in Oil/Water Food Grade Microemulsions in the Presence of Polyols and Ethanol. J. Agric Food Chem. 49, 2552-2562 (2001).

25. Mason, T. G., Wilking, J. N., Meleson, K., Chang, C. B. \& Graves, S. M. Nanoemulsions: formation, structure, and physical properties. Journal of Physics: Condensed Matter. 18, R635-R666 (2006).

26. Althanyan, M. S., Assi, K. H., Clark, B. J. \& Hanaee, J. Microemulsion high performance liquid chromatography (MELC) method for the determination of terbutaline in pharmaceutical preparation. J Pharm Biomed Anal. 55, 397-402 (2011).

27. National pharmacopoeia commission. Chinese Pharmacopoeia. 156-157 (2015).

\section{Acknowledgements}

Research was supported by the National Natural Science Fund of China (81873038, 81872976, 81303245), Excellent Researcher Award Program of Anhui Province (gxyqZD2016135), Science Program of Anhui province (KJ2015A061, KJ2016A398), Science and Technology Program of Chizhou (17kz010107), the Key Project Foundation of Oversea Visiting and Research for the Excellent Young and Middle-aged Faculties in Universities of Anhui Province in China (No: gxgwfx2018042).

\section{Author contributions}

H.W. and A.Z. designed the experiments. Z.Z., H.Y. and X.L. performed the experiments, analyzed the raw date, and wrote the manuscript. H.Y. was involved in revision of the manuscript. All authors read and approved the final version of manuscript.

\section{Competing interests}

The authors declare no competing interests.

\section{Additional information}

Correspondence and requests for materials should be addressed to H.-F.W. or A.Z.

Reprints and permissions information is available at www.nature.com/reprints.

Publisher's note Springer Nature remains neutral with regard to jurisdictional claims in published maps and institutional affiliations.

Open Access This article is licensed under a Creative Commons Attribution 4.0 International

License, which permits use, sharing, adaptation, distribution and reproduction in any medium or format, as long as you give appropriate credit to the original author(s) and the source, provide a link to the Creative Commons license, and indicate if changes were made. The images or other third party material in this article are included in the article's Creative Commons license, unless indicated otherwise in a credit line to the material. If material is not included in the article's Creative Commons license and your intended use is not permitted by statutory regulation or exceeds the permitted use, you will need to obtain permission directly from the copyright holder. To view a copy of this license, visit http://creativecommons.org/licenses/by/4.0/.

(C) The Author(s) 2019 